\title{
HUBUNGAN ANTARA DAYA LEDAK OTOT KAKI, KOORDINASI MATA- TANGAN, DAN RASA PERCAYA DIRI DENGAN HASIL KETERAMPILAN JUMPING SERVICE BOLA VOLI
}

\author{
DOMI BUSTOMI \\ Universitas Islam “45” Bekasi \\ dbustomi01@gmail.com
}

\begin{abstract}
ABSTRAK
Hasil pengujian hipotesis terdapat hubungan positif antara Daya Ledak Otot Kaki $\left(\mathrm{X}_{1}\right)$ dengan Hasil Keterampilan Jumping service Bola Voli (Y), Hal tersebut berarti bahwa Daya Ledak Otot Kaki memberi kontribusi sebesar 68\% terhadap Hasil Keterampilan Jumping service Bola Voli. Terdapat hubungan positif antara Koordinasi Mata-tangan $\left(\mathrm{X}_{2}\right)$ dengan hasil keterampilan jumping service bola voli $(\mathrm{Y})$, Hal tersebut berarti bahwa koordinasi mata-tangan memberi kontribusi sebesar 78\% terhadap hasil keterampilan jumping service bola voli. Terdapat hubungan positif antara Rasa Percaya Diri $\left(\mathrm{X}_{3}\right)$ dengan hasil keterampilan jumping service bola voli $(\mathrm{Y})$, Hal tersebut berarti bahwa rasa percaya diri memberi kontribusi sebesar $46 \%$ terhadap hasil keterampilan jumping service bola voli. Terdapat hubungan positif antara power tungki $\left(\mathrm{X}_{1}\right)$, koordinasi mata-tangan $\left(\mathrm{X}_{2}\right)$, rasa percaya diri $\left(\mathrm{X}_{3}\right)$ dengan hasil keterampilan jumping service bola voli (Y), Sehingga scara bersama-sama Daya Ledak Otot Kaki, koordinasi mata-tangan dan rasa percaya diri memberi sumbangan sebesar $82 \%$ dengan hasil keterampilan jumping service bola voli. Jadi dapat disimpulkan bahwa Daya Ledak Otot Kaki, koordinasi mata-tangan, dan rasa percaya diri memiliki hubungan yang signifikan dengan hasil keterampilan jumping service bola voli.
\end{abstract}

Keyword: Percaya diri, Hasil Keterampilan jumping service bola voli.

\section{PENDAHULUAN}

Perkembangan olahraga di indonesia saat ini tidak sedikit membicaraan tentang manfaat voli, sebagai olahraga tim, untuk individu. Manfaat ini dikatakan lebih besar daripada olahraga yang lebih populer lainnya. Mungkin yang paling populer adalah olahraga tim sepak bola tetapi ada juga olahraga lain, seperti bola voli, yang memiliki efek penting yang sama bagi para peserta. Hal ini senada dengan yang dikemukakan Maria Markella (2008) yang mengungkapkan bahwa: 
Nowadays there is much talk about the benefit of volleyball, as a team sport, to individuals. This benefit is said to be even bigger than that of other more popular sports. Maybe the most popular of team sports is soccer but there are also others, like volleyball, that have the same important effects for the participants.

Secara garis besar teknik dasar permainan bola voli, Beutelstahl (2005;9-27) menyatakan bahwa bola voli mempunyai bentuk-bentuk teknik dasar sebagai berikut: 1) Servis dimaksudkan sebagai pukulan permulaan dengan bola untuk memulai permainan. Akantetapi servis ini kemudian berkembang menjadi suatu senjata yang ampuh untuk menyerang. a) Hook servis yang diperkenalkan oleh orang Estonia. b) Floating servis yang dikembangkan oleh orang Jepang. Jenis servis yang paling umum adalah: a) Under arm servis atau servis lengan bawah. b) Hook servis atau servis kait. c) Floating servis atau servis melayang. d) Jump servis atau servis sambil loncat. 2) The dig ini dimaksudkan, penerimaan bola dengan gaya menggali. 3) Volley atau set dimaksudkan, sentuhan tangan melambungkan bola sedemikian rupa, sehingga teman kita mendapat kesempatan untuk men-smash bola tersebut. Tujuan dari orang yang memainkan volley adalah: Memberi kesempatan kepada teman untuk menyerang musuh. Jenis-jenis volley yang umum: a) Front volley atau voli depan. b) Overhead volley atau voli diatas kepala. c) Jump volley to front and back atau voli lompat kedepan dan kebelakang.

Schmidt mencoba menggambarkan definisi keterampilan tersebut dengan meminjam definisi yang diciptakan oleh E.R. Guthrie, yang mengatakan bahwa: "Keterampilan merupakan kemampuan untuk membuat hasil akhir dengan kepastian yang maksimum dan pengeluaran energi dan waktu yang minimum." Sedangkan Singer menyatakan bahwa "keterampilan adalah derajat keberhasilan yang konsisten dalam mencapai suatu tujuan dengan efisien dan efektif" dalam Suprastyo(2011).

\section{Spike}

Salah satu teknik dasar dalam permainan bola voli adalah tehnik spike. Spike merupakan salah satu teknik serangan dalam permainan bola voli yang memiliki rangkaian gerak yang kompleks. Yudiana dan Subroto $(2010 ; 56)$ menjelaskan :

Untuk Melakukan Spike dengan baik menurut Jeff Lucas harusnya memperhatikan faktor-faktor berikut :

Berdiri dengan salah satu kaki dibelakang sesuai dengan kebiasaan individu (tergantung smasher normal atau kidal).Langkahkan kaki satu langkah ke depan (pemain yang baik dapat mengambil ancang-ancang sebanyak 2-4 langkah).kemudianlengan mulai bergerak ke belakang. Berat badan berangsur-angsur 
merendah untuk membantu tolakan. 2) Langkahkan kaki selanjutnya hingga kedua telapak kaki hampir sejajar dan salah satu kaki agar kedepan sedikit untuk mengerem gerak ke depan dan sebagai persiapan melompat ke arah vertikal. Ayunkan kedua lengan ke belakang atas sebatas kemampuan kaki ditekuk sehingga lutut membuat sudut $\pm 110^{\circ}$, badan siap untuk melompat dengan berat badan lebih banyak bertumpu pada kaki yang di depan. 3) Mulailah melompat dengan tumit dan jari kaki terhentak lantai dan mengayunkan kedua lengan ke depan atas, saat kedua kaki mendorong naik ke atas, telapak kaki, pergelangan tangan, pinggul dan batang tubuh digerakkan serasi merupakan rangkaian gerak yang sempurna, gerakan eksplosif dan loncatan vertikal. 4) Jarak antara di depan atas sejangkauan lengan memukul, segera lecutkan lengan ke belakang kepala dan dengan cepat lecutkan ke depan sejangkauan lengan terpanjang dan tertinggi terhadap bola. 5) Mendarat dengan kedua kaki mengeper, lutut lentur saat mendarat untuk meredam perkenaan kaki dengan lantai, mendarat dengan jari-jari kaki (telapak kaki bagian depan) dan sikap badan condong ke depan.

\section{Jumping service}

Jumping service ini biasanya dilakukan oleh para pemain voli profesional.Untuk melakukan jumping service diperlukan latihan khusus.Kekuatan lengan dan polos harus baik,sehingga bola bisa meluncur keras dan menukik tajam.Jumping service banyak diterapkan oleh pemain voli hebat untuk memperoleh point melalui service.

Teknik jump serve dalam bola voli termasuk kategori teknik overhand serve. Pemain yang akan melakukan serve melempar bola tinggi ke udara, dan sebelumnya pemain melakukan persiapan di luar garis belakan lapangan. Setelah itu pemain melakukan langkah penyesuaian terhadap bola yang bergerak turun, kemudian ia akan melompat dan memukul bola tersebut. Tahap gerakan dalam jumping service

1. Pemain harus memiliki power cukup untuk memukul bola.

2. Ambil 4 langkah kebelakang dari garis luar garis belakang lapangan.

3. Lempar bola dari samping ke arah depan seting-tingginya agar mudah bola di kontrol.

4. Ambil langkah termudah agar bisa menjangkau bola diudara.

5. Ketika bola hendak turun kebawah, loncat dan ayunkan tangan anda kebelakang seperti melakukan smash.

6. Sebelum memukul bola, bolah harus berada di atas kepala atau tepat diujung telapak tangan dan pukul bola dengan kencang dan terarah. 


\section{Daya Ledak Otot Kaki}

Daya ledak otot adalah kemampuan otot atau sekelompok otot melakukankerja secara eksplosif, dipengaruhi oleh kekuatan dan kecepatan kontraksi otot. Daya ledak adalah kemampuan seseorang untuk menggunakan kekuatan maksimal yang dikerahkan dalam waktu sependek-pendeknya dalam hal ini dinyatakan bahwa daya ledak (power) sama dengan kekuatan dikali kecepatan. Daya ledak adalah kemampuan sebuah untuk mengatasi tahanan beban dengan kecepatan tinggi dalam satu gerakan yang utuh. Pendapat Knuttgen and Kraemer dalam Thomas R. Baechle Roger W, Strengththe maximal force that a muscle or muscle group can generate at a specified velocity. Maksudnya Kekuatan adalah kerja maksimal otot atau sekelompok otot yang dapat menghasilkan kecepatan tertentu. Sedangkan menurut Len Kravitz kekuatan otot adalah kemampuan otot yang menggunakan tenaga maksimal, untuk mengangkat beban. Sementara itu Rusli Lutan mengemukakan bahwa kekuatan merupakan komponen yang sangat penting untuk meningkatkan kondisi fisik seseorang secara keseluruhan.

Jadi yang dimaksud dengan Daya Ledak Otot Kaki dalam penelitian ini adalah kemampuan seseorang dalam menggunakan sekelompok otot kaki untuk menghasilkan kekuatan yang maksimal pada waktu melakukan loncat / jumping dalam permainan bola voli, agar bola dapat melaju dengan cepat dan keras sehingga sulit diterima oleh lawan. Dr. Widiastuti menyatakan Pengukuran power kaki ini dilakukan dengan tes vertical jump dengan satuan ukuran meter.

\section{Koordinasi Mata-tangan}

Menurut teori taksonomi yang dikemukakan oleh Harrow dalam Mahendra (2007;27-28), gerakan manusia dikelompokkan sebagai berikut 1) Reflex Movement, 2) Basic Fundamental Movement, 3) Perceptual Abilities, 4) Physical Abilities, 5) Skill Movement, 6) Non-discursive Communication.

Agus Mahendra (2007;38) menjelaskan bahwa Termasuk ke dalam kemampuan gerak terkoordinasi adalah koordinasi mata-tangan yang berhubungan dengan kemampuanmemilihsuatu obyek dan mengkoordinasikannya (obyek yang dilihat dengan gerakan-gerakan yang di atur). Contohnya adalah dalam permaianan tenis meja. Kegiatan koordinasi mata-tangan menghendaki pengamatan yang tepat dan pengaturan dari gerak.

Sementara itu Broer dan Zernicke (Harsono 1988;219) mengemukakan bahwa: "The well-timed and well-balanced functioning together of several muscles in a single 
movement" yang artinya koordinasi merupakan perpaduan fungsi otot secara tepat dan seimbang menjadi pola gerak.

Dengan demikian dari beberapa pandapat diatas bahwa dalam mengkoordinasikan penglihatan mata dan tangan sebagai anggota badan yang apabila peneliti hubungkan dalam penelitian ini yaitu fungsi untuk melihat ketepatan bola pada saat di udara sampai titik ketinggian yang dapat dijangkau atau dipukul oleh seorang spiker dalam melakukan Jumping service bola voli.

\section{Rasa Percaya Diri}

De Angelis mengemukakan bahwa "rasa percaya diri sebagai keyakinan pada kemampuan diri sendiri yang mana percaya diri itu berawal dari tekad pada diri sendiri untuk melakukan segala sesuatu yang diinginkan dan dibutuhkan dalam hidup". Rasa percaya diri lebih menekankan pada kepuasan yang dirasakan individu terhadap dirinya, dengan kata lain individu yang percaya diri adalah individu yang merasa puas pada dirinya sendiri (Liendenfield). Hal ini mendorong individu untuk melakukan sesuatu yang berkaitan dengan keberhasilan, Demikian pula McClelland menyatakan bahwa kepercayan diri merupakan control internal perasaan seseorang. Kemudian Cox mengemukakan bahwa „dimensi efisiensi kognitif berkenaan dengan tingkat keyakinan atlet tentang kemampuannya bahwa dirinya secara mental dapat memfokuskan dan menjaga konsentrasinya serta membuat keputusan yang tepat, dan mengelola pikirannya untuk keberhasilan kinerjanya. Sedangkan dimensi latihan dan keterampilan fisik berkenaan dengan tingkat keyakinan atlet tentang kemampuan dirinya untuk mampu melakukan latihan dan keterampilan yang bersifat fisik yang dibutuhkan untuk keberhasilan kinerjanya Serta dimensi resiliensi berkenaan dengan tingkat keyakinan atlet tentang kemampuan dirinya untuk mampu fokus dan bangkit kembali setelah kinerjanya yang tidak memuaskan, mampu mengatasi berbagai masalah dan keraguan, serta mampu untuk menampilan keterampilan dan permainan terbaiknya (Cox; Vealey \& Chase, 2013)

\section{METODE PENELITIAN}

Metode penelitian yang digunakan dalam peneltian ini adalah metode survey dengan rancangan korelasional. Penelitian survey bersifat non-eksperimen, karena peneliti tidak melakukan intervensi variabel-variabel yang diteliti. Pnelitian ini bersifat korelasional karena peneliti berusaha menyelidiki hubungan antara beberapa variabel penelitian yaitu tiga variabel bebas, Daya Ledak Otot Kaki $\left(\mathrm{X}_{1}\right)$, Koordinasi Matatangan $\left(\mathrm{X}_{2}\right)$, dan Rasa Percaya Diri $\left(\mathrm{X}_{3}\right)$. Serta satu variabel terikat yaitu Keterampilan Jumping service $(\mathrm{Y})$. Ketiga Variabel Bebas $\left(\mathrm{X}_{1}, \mathrm{X}_{2}\right.$, dan $\left.\mathrm{X}_{3}\right)$ dihubungkan dengan 
Variabel terikat (Y) dengan pola hubungan : (1) hubungan antara variabel $\left(\mathrm{X}_{1}\right)$ dengan varibel $(\mathrm{Y}),(2)$ hubungan antara variabel $\left(\mathrm{X}_{2}\right)$ dengan variabel $(\mathrm{Y}),(3)$ hubungan antara variabel $\mathrm{X}_{3}$ dengan variabel $(\mathrm{Y})$, dan (4) hubungan antara variabel $\mathrm{X}_{1}, \mathrm{X}_{2}$, dan variabel $\mathrm{X}_{3}$ secara bersama-sama dengan variabel $\mathrm{Y}$. Keempat pola hubungan variabel tersebut merupakan konstelasi masalah daam penelitian ini. Pola hubungan antara variabel penelitian terlihat pada gambar berikut:

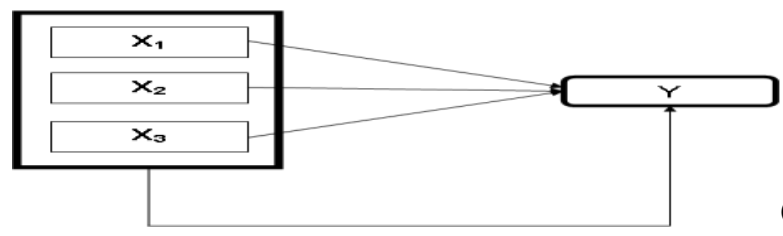

Gambar 2

\section{Korelasi Hubungan Antara $X_{1}, X_{2}, X_{3}$ dengan Y}

Keterangan ;

$\mathrm{Y} \quad$ : Jumping service

$\mathrm{X}_{1} \quad$ : Daya Ledak Otot Kaki

$\mathrm{X}_{2}$ : Koordinasi Mata-tangan

$\mathrm{X}_{3} \quad$ : Tingkat Percaya Diri

\section{Teknik Pengumpulan Data}

Data yang dibutuhkan dalam penelitian ini adalah data variabel Daya Ledak Otot Kaki, Koordinasi Mata-tangan, dan Rasa Percaya Diri dan hasil Keterampilan Jumping service Bola Voli yang di kumpulkan tes dan pengukuran juga angket.

Langkah-langkah yang dilakukan dalam proses pengumpulan data tersebut adalah sebagai berikut : (1) melakukan uji coba instrument, (2) menganalisis data hasil uji coba instrument, (3) melakuan tes dan pengukuran variabel Daya Ledak Otot $\operatorname{Kaki}\left(\mathrm{X}_{1}\right)$, Koordinasi Mata-tangan $\left(\mathrm{X}_{2}\right)$, Rasa percaya diri $\left(\mathrm{X}_{3}\right)$, dan Keterampilan Jumping service Bola Voli (Y).

Untuk mendapatkan data yang akan diolah dalam penelitian ini, maka digunakan instrument sebagai berikut ; (1) Keterampilan Jumping service bola voli (Y) dengan instrument tes Spike, (2) tes loncat tegak (Vertical Jump Test) untuk mengukur kemampuan meloncat keatas, (3) koordinasi dengan tes (Wall PassTest) untuk mengukur Koordinasi Mata-tangan, (4) angket atau Questionnaire untuk mengukur tingkat percaya diri. 


\section{Uji Normalitas}

Uji normalitas data menggunakan uji One-Sample Kolmogorov-Smirnov Test” (Liliefors). Jika Sig > 0,05 maka data berdistribusi normal, jika Sig < 0,05, maka data tidak berdistribusi normal. nilai signifikansi untuk Daya Ledak Otot Kaki sebesar 0,092; untuk Koordinasi Mata-tangan sebesar 0,111; untuk Rasa Percaya Diri sebesar 0,143 dan untuk Hasil Keterampilan Jumping service bola voli sebesar 0,167. Karena signifikansi untuk seluruh variabel lebih besar dari 0,05 maka dapat disimpulkan bahwa data pada variabel Daya Ledak Otot Kaki, Koordinasi Mata-tangan, Rasa Percaya Diri, dan Hasil Keterampilan Jumping service bola voli berdistribusi Normal. Angka statistik menunjukkan semakin kecil nilainya maka distribusi data semakin normal.

\section{Uji Linearitas}

Pengujian pada SPSS dengan menggunakan Tes for Linearity dengan pada taraf signifikansi 0,05. Dua variabel dikatakan mempunyai hubungan yang linear bila signifikansi (Linearity) kurang dari 0,05. Adapun hasil tersebut dapat disajikan dalam tabel sebagai berikut :

Uji Linearitas variabel Power Tngkai $\left(\mathrm{X}_{1}\right)$ dengan Hasil Keterampilan Jumping service (Y) Diketahui bahwa nilai signifikansi pada Linearity sebesar 30,809. Karena signifikansi lebih besar dari 0,05 maka dapat disimpulkan bahwa variabel Daya Ledak Otot Kaki terdapat hubungan yang linier.

Uji Linearitas variabel Koordinasi Mata-tangan $\left(\mathrm{X}_{2}\right)$ dengan Hasil Keterampilan Jumping service (Y), Diketahui bahwa nilai signifikansi pada Linearity sebesar 56,514. Karena signifikansi lebih besar dari 0,05 maka dapat disimpulkan bahwa antara variabel Koordinasi Mata-tangan terdapat hubungan yang linier.

Uji Linearitas variabel Rasa Percaya Diri $\left(\mathrm{X}_{3}\right)$ dengan hasil Keterampilan Jumping service Bola Voli (Y), Diketahui bahwa nilai signifikansi pada Linearity sebesar 11,868. Karena signifikansi lebih dari 0,05 maka dapat disimpulkan bahwa antara variabel Rasa Percaya Diri terdapat hubungan yang linier.

\section{Pengujian Hipotesis}

Hasil pengujian hipotesis pertama, terdapat hubungan positif antara Daya Ledak Otot Kaki $\left(\mathrm{X}_{1}\right)$ dengan Hasil Keterampilan Jumping service Bola Voli (Y), hal tersebut ditunjukan oleh koefisien koerlasi (ry $)_{\text {) }}$ sebesar 0,825 dengan persamaan regresi $\hat{Y}=8,834+0,819 X_{1}$. Koefisien determinasi sebesar 0,680 . Hal tersebut berarti 
bahwa Daya Ledak Otot Kaki memberi kontribusi sebesar 68\% terhadap Hasil Keterampilan Jumping service Bola Voli.

Kedua, terdapat hubungan positif antara Koordinasi Mata-tangan $\left(\mathrm{X}_{2}\right)$ dengan hasil keterampilan jumping service bola voli (Y), hal tersebut ditunjukan oleh koefisien koerlasi (ry2) sebesar 0,880 dengan persamaan regresi $\hat{Y}=5,394+0,884 X_{2}$. Koefisien determinasi sebesar 0,775 . Hal tersebut berarti bahwa koordinasi mata-tangan memberi kontribusi sebesar $78 \%$ terhadap hasil keterampilan jumping service bola voli.

Ketiga, terdapat hubungan positif antara Rasa Percaya Diri $\left(\mathrm{X}_{3}\right)$ dengan hasil keterampilan jumping service bola voli (Y), hal tersebut ditunjukan oleh koefisien koerlasi ( $\mathrm{ry}_{3}$ ) sebesar 0,679 dengan persamaan regresi $\hat{Y}=15,970+0,676 \mathrm{X}_{3}$. Koefisien determinasi sebesar 0,461 . Hal tersebut berarti bahwa rasa percaya diri memberi kontribusi sebesar $46 \%$ terhadap hasil keterampilan jumping service bola voli.

Keempat, terdapat hubungan positif antara power tungki $\left(\mathrm{X}_{1}\right)$, koordinasi matatangan $\left(\mathrm{X}_{2}\right)$, rasa percaya diri $\left(\mathrm{X}_{3}\right)$ dengan hasil keterampilan jumping service bola voli (Y), hal tersebut ditunjukan oleh koefisien koerlasi sebesar 0,909 dengan persamaan regresi $\left.\hat{\mathrm{Y}}=3,590+0,388) \mathrm{X}_{1}+0,726\right) \mathrm{X}_{2}+(-0,193) \mathrm{X}_{3}$. Sumbangan ketiga variabel tersebut ditunjukkan oleh koefisien determinasi sebesar 0,826. Sehingga scara bersama-sama Daya Ledak Otot Kaki, koordinasi mata-tangan dan rasa percaya diri memberi sumbangan sebesar $82 \%$ dengan hasil keterampilan jumping service bola voli.

Jadi dapat disimpulkan bahwa Daya Ledak Otot Kaki, koordinasi mata-tangan, dan rasa percaya diri memiliki hubungan yang signifikan dengan hasil keterampilan jumping service bola voli.

\section{KESIMPULAN}

Berdasarkan deskripsi teori dan kerangka berpikir yang diajukan, maka dapat ditarik kesimpulan berikut :

1)Hasil pengujian hipotesis pertama terdapat hubungan positif antara Daya Ledak Otot Kaki (X1) dengan hasil keterampilan Jumping service (Y). Hasil penelitian ini menunjukkan bahwa Daya Ledak Otot Kaki memiliki hubungan dengan hasil keterampilan Jumping service dalam olahraga bola voli. 2) Hasil pengujian hipotesis kedua terhadap hubungan positif antara koordinasi mata dan tangan (X2), dengan hasil keterampilan jumping service (Y). Hasil penelitian ini menunjukkan bahwa koordinasi mata-tangan memiliki hubungan dengan hasil keterampilan jumping service dalam cabang olahraga bola voli. 3) Hasil pengujian hipotesis ketiga terhadap hubungan positif antara rasa percaya diri (X3) dengan hasil keterampilan jumping service bola 
voli (Y). Hasil penelitian ini menunjukkan bahwa rasa percaya diri memiliki hubungan dengan keterampilan hasil keterampilan jumping service dalam cabang olahraga bola voli. 4) Hasil pengujian hipotesa keempat terhadap hubungan positif antara Daya Ledak Otot Kaki (X1) koordinasi mata-tangan (X2) dan rasa percaya diri (X3) secara bersama-sama terhadap hasil keterampilan jumping service pada cabang olahraga bola voli (Y) yang diperoleh dari koefisien korelasi R dengan persamaan regresi. Ini berarti, bahwa semakin Daya Ledak Otot Kaki, koordinasi mata-tangan dan rasa percaya diri pemain bola voli, makin baik pula hasil keterampilan jumping service pada pemain bola voli. Dan sebaiknya, makin rendah Daya Ledak Otot Kaki, koordinasi mata-tangan dan rasa percaya diri pemain bola voli, makin rendah pula hasil keterampilan jumping service pada olahraga bola voli. Oleh karena itu, Daya Ledak Otot Kaki, koordinasi mata-tangan dan rasa percaya diri merupakan tiga variabel yang perlu diperhatikan untuk mendapatkan hasil keterampilan jumping service dalam olahraga bola voli, walaupun salah satu dari ketiga variabel tersebut hanya sebagai pendukung.

\section{DAFTAR PUSTAKA}

Agus Mahendra, Teory Belajar Motorik. (FPOK. UPI Bandung. 2007)

Achmadr Damiri, Anatomi Manusia. Bandung: (FPOK IKIP Bandung. 1994)

Dieter, Beutelstahl. (2005). Belajar bermain bola voli. Bandung: CV. Pionir Jaya.

Bachtiar. (2007). Permainan Besar II Bola Voli dan Bola Tangan. Jakarta. Universitas Terbuka.

Harsono, Coaching Dan Aspek-aspek Psikologis Dalam Coaching. (Jakarta: C.V. Tambak Kusuma, 1988).

Ivan Nur Safrin (http://ivanyizha.blogspot.com/2012/05/spike.html) diunggah. Selasa, 15 Mei 2012 di 18.44.

Jeff Lucas (http://www.partnersforhealthykids.com/VBall/Spiking.html)

Laberge, Monique. Hand-Eye Coordination (Online). Tersedia: http://www.answers.com/topic/hand-eye-coordination. [28 Agustus 2010]. 2004.

Maria Markella. (2008). The Benefits of a Great Team Sport Bola Voli Today (Online). Tersedia:http://www.kidzworld.com/article/4963-playing-volleyball.

Agustus 2010) 
BIORMATIKA Jurnal Ilmiah FKIP Universitas Subang Vol. 5 No 01 Februari 2019 ISSN (p) 2461-3961 (e) 2580-6335

PPS UNJ. Buku Pedoman Penulisan Tesis Dan Disertasi. (2012).

Program SPSS 19.0 for Windows. (2012)

Theng, K.H. Permainan Volleyball Modern. Bandung: Yayasan Kanisius. 1973.

Viera, B. L. dan Fergusson B.J. (1996). Bola Voli Tingkat Pemula. Jakarta: PT. Raja Grapindo Persada.

Yudiana, Y. Subroto, T. (2010). Modul Permainan Bola Voli. Bandung. FPOK-UP. 